\title{
The neural basis for auditory and audiovisual speech perception
}

\author{
Jonathan E. Peelle \\ Department of Otolaryngology, Washington University in St. Louis, St. Louis MO USA
}

To appear as:

Peelle JE (In press) The neural basis for auditory and audiovisual speech perception. In: The Routledge Handbook of Phonetics (Katz and Assmann, eds). Routledge.

Please address correspondence to:

Dr. Jonathan Peelle Department of Otolaryngology

Washington University in Saint Louis

660 South Euclid, Box 8115

Saint Louis, MO 63110 
Although much focus in phonetics is (understandably) on the acoustic speech signal, ultimately the sound waves produced by a speaker need to be interpreted by a listener's brain. This concept is beautifully illustrated in the classic "speech chain" (Denes and Pinson, 1993), a version of which is shown in Figure 1. In this chapter I review the areas of the brain involved in the perception of various levels of spoken language, from isolated phonemes to narratives.
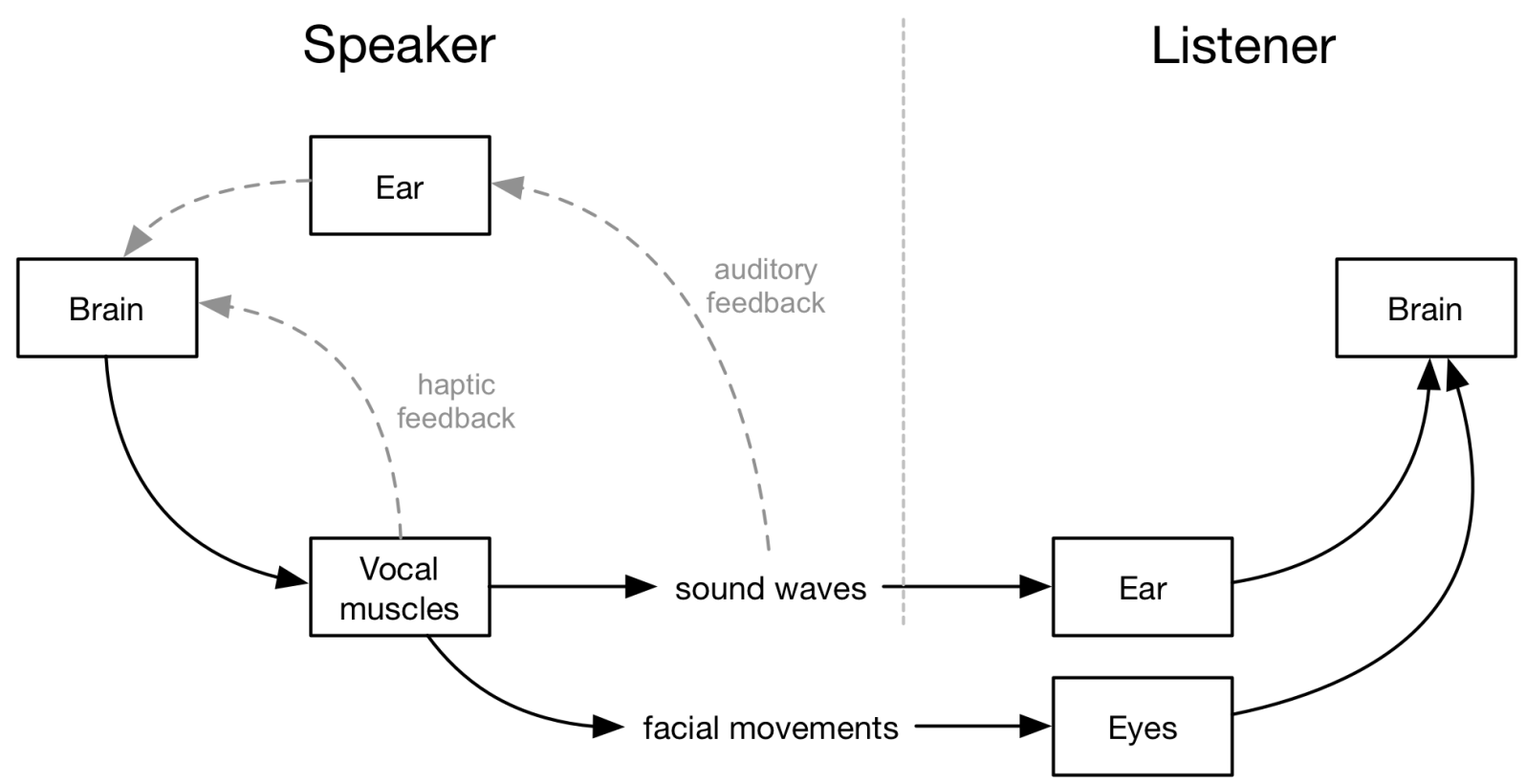

Figure 1. Re-creation of the classic speech chain of Denes and Pinson (1993). Speech functions to communicate a language message from the brain of the speaker to the brain of the listener, transmitted acoustically subject to a variety of constraints on its production, transmission, and reception.

\section{Basic principles}

\section{What do we mean by "speech"?}

A fundamental challenge in discussing the neural basis for speech perception is defining what we mean by the term "speech": As illustrated in Figure 2, isolated phonemes, nonwords, words, and sentences are all associated with different (though frequently overlapping) patterns of brain activity (Peelle, 2012). Thus, although it is common for researchers to talk about "speech perception" without specifying the category of speech they mean, in fact it is important to be specific regarding the types of acoustic and linguistic information listeners are processing. In the sections below, I will review these different levels of speech processing to make these distinctions clear. The full picture, of course, is slightly more complicated because of the overlapping levels of processing across different types of stimuli. Successfully isolating specific stages of acoustic or linguistic processing requires careful attention to the experimental manipulations. 


\section{Type of processing}

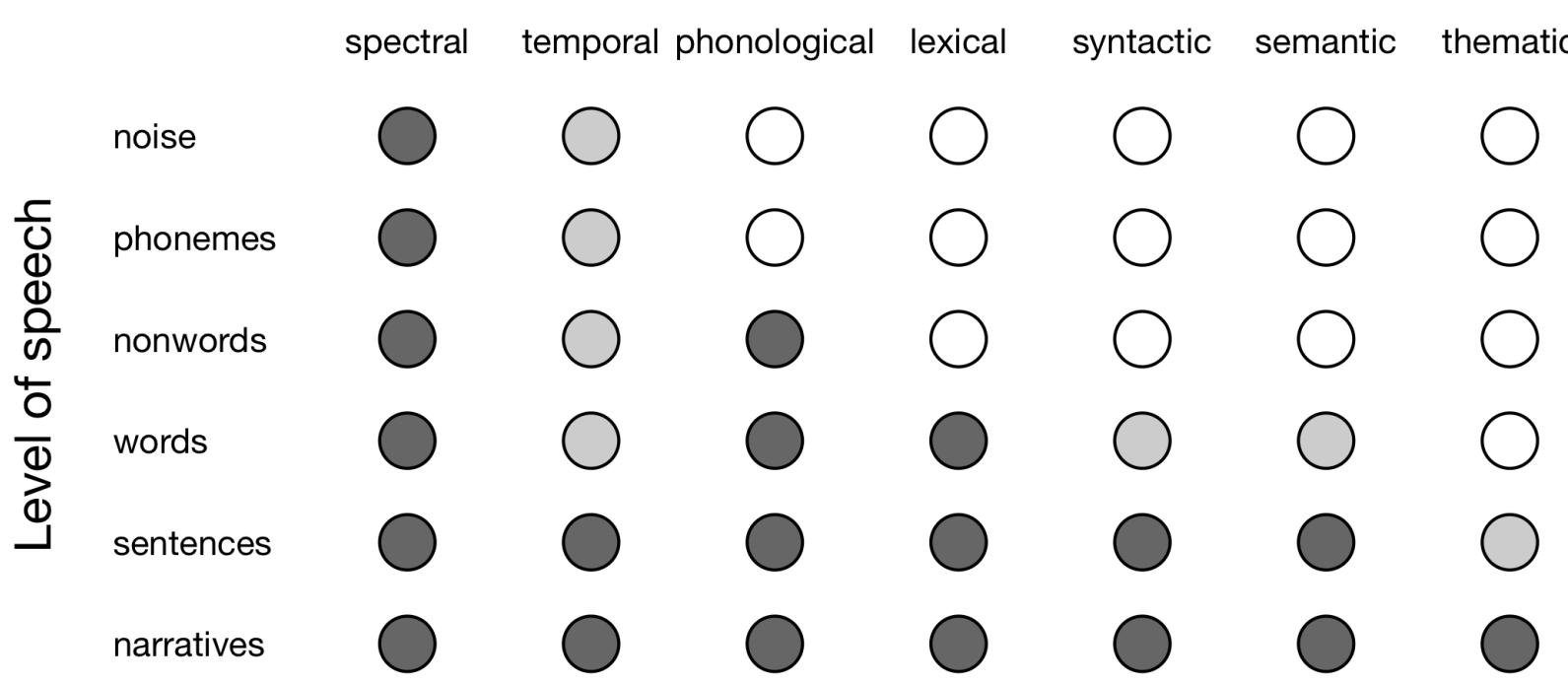

Figure 2. Illustration of some types of acoustic and linguistic processing (top) involved in various levels of speech perception (listed along the left). Darker circles indicate a stronger reliance on a particular type of processing. Although different types of speech stimuli have different processing requirements, there is also overlap in processing across different stages (for example, both single words and sentences require lexical and semantic processing, although the specific demands may differ). Spectral processing refers to information in multiple frequency ranges, and temporal processing refers to changing information over time. Phonological processing involves the arrangement or pattern of speech sounds. Lexical representations are learned word forms. Syntactic processing refers to understanding relationships between words; although typically thought of in the context of sentences, single words can also have syntactic information (for example, verbs imply an actor and an object). Semantic processes are associated with concept representations of single words and are also important in interpreting connected speech. In this context, thematic processing refers to overarching organizing themes found in narratives that tie the story together across multiple sentences.

On a related point, when considering the results of neuroimaging studies, it is always critical to consider the comparison or control condition to which speech is being compared. Processing acoustic stimuli that are not speech (such as pure tones, temporally modulated noise, or musical "rain") results in substantial activation in bilateral temporal cortex (Overath et al., 2010, Griffiths et al., 1998). This acoustic-related activity may occur in regions similar to those used for various levels of speech processing, and thus they make useful control conditions to better isolate activity that is preferential for speech.

\section{Anatomical connectivity}

Before examining how the brain's activity changes when processing various types of speech, it is useful to consider the anatomical connectivity of speech-sensitive regions, starting with auditory cortex. These connections help outline a neural scaffolding that we might reasonably expect to be engaged in processing spoken language.

Data from nonhuman primates reveals a core auditory cortex that reflects tonotopic organization and responds to pure-tone stimuli (Kaas and Hackett, 2000). Outside the auditory core are belt and parabelt regions which show sensitivity to stimuli of increasing acoustic complexity, including broadband noise (Kaas et al., 1999). 
Beyond auditory cortex, anatomical studies in primates have long emphasized the extensive and highly parallel anatomical coupling between auditory and frontal cortices (Petrides and Pandya, 2009, Hackett et al., 1999, Seltzer and Pandya, 1989). A summary figure of anatomical connectivity in monkey and cat is shown in Figure 3. Consistent with anatomical connectivity studies, electrophysiological findings in nonhuman primates show responses to auditory stimuli in frontal cortex, suggesting frontal involvement as a natural part of auditory processing (Romanski and Goldman-Rakic, 2002, Romanski et al., 1999).

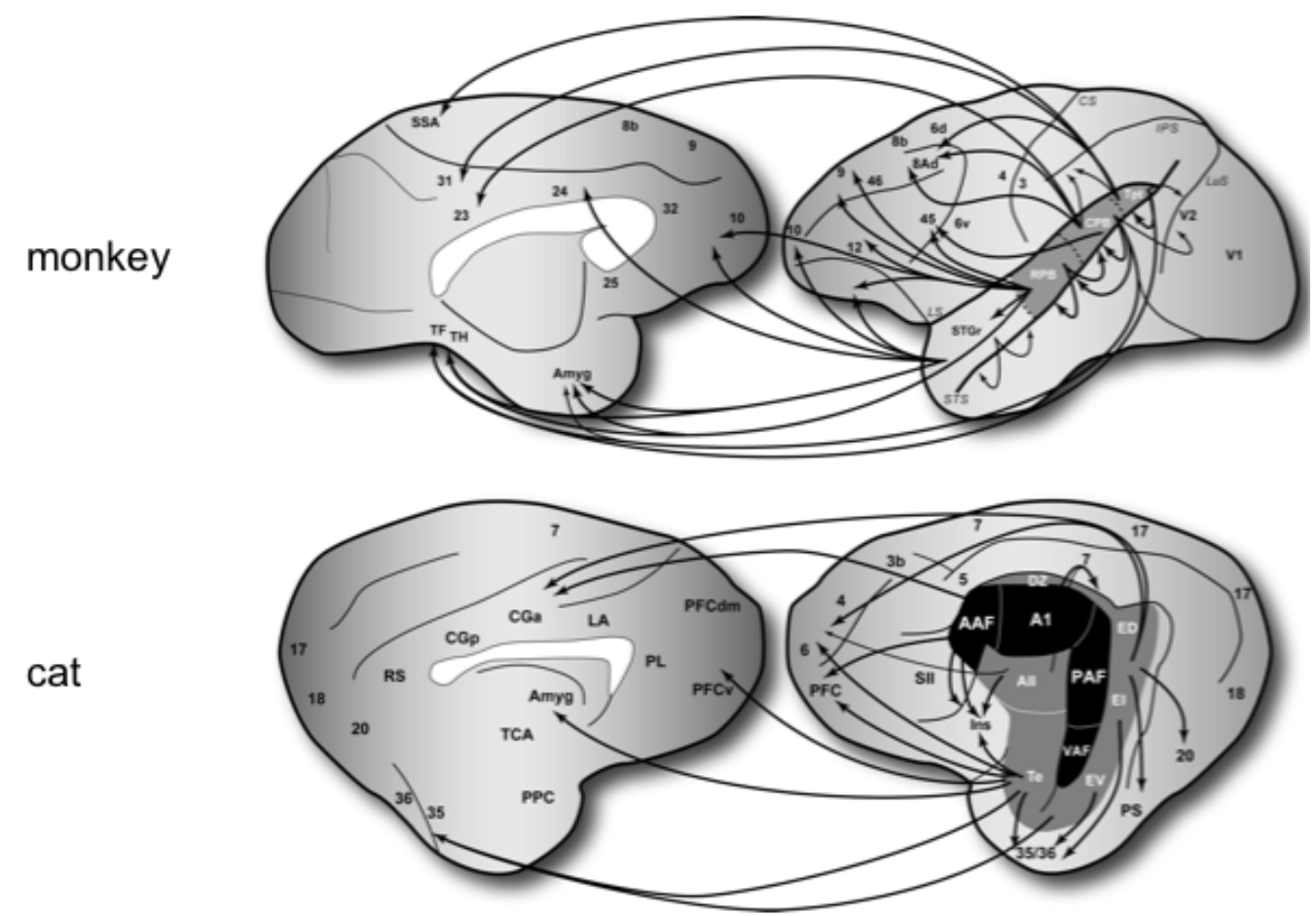

Figure 3. Summary figure of connectivity from auditory cortex in monkey (top) and cat (bottom). Reproduced from Hackett (2011). Numerous pathways exist to transmit information outside of auditory cortex in both the ipsilateral and contralateral hemispheres.

These anatomical and functional connections have lent support to a dual-stream framework for speech processing (Hickok and Poeppel, 2007, Rauschecker and Scott, 2009, Hickok and Poeppel, 2000) consisting of a dorsal stream and a ventral stream. The dorsal stream travels from auditory cortex along the arcuate fasciculus, through parietal lobe and into dorsal premotor cortex; the ventral stream proceeds from auditory cortex towards the anterior temporal lobe and through the uncinate fasciculus into ventral inferior frontal gyrus (IFG). Although animal data indicate more than these two pathways for information leaving auditory cortex (Hackett, 2011), the dual stream model has proved to be a useful framework encompassing many of the main cortical areas involved in speech processing. 


\section{Neural systems supporting auditory speech perception}

In the sections below, I review the cortical regions involved in processing various levels of auditory speech, from isolated phonemes through narratives, following the distinctions outlined in Figure 2. A schematic of the main regions is shown in Figure 4.
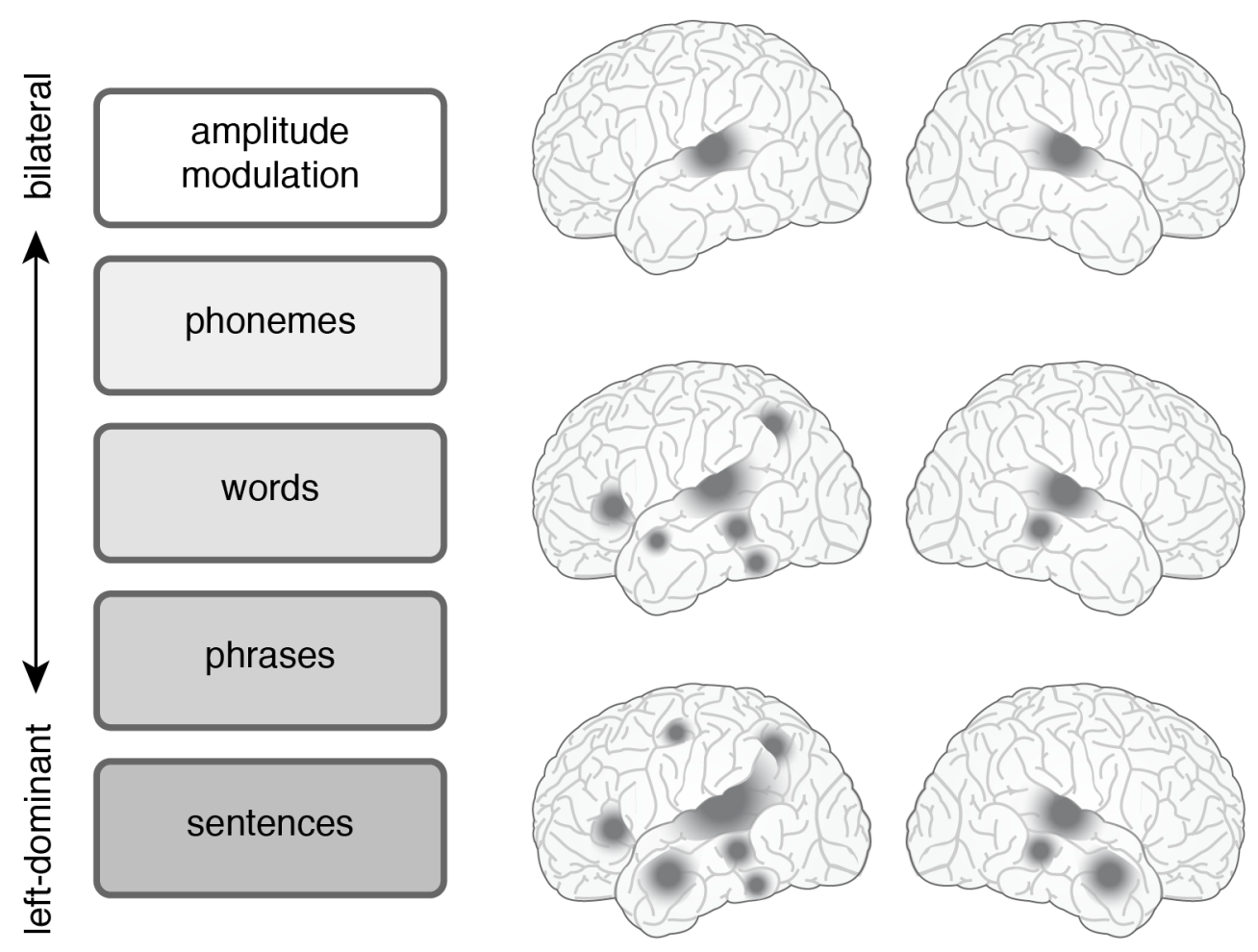

Figure 4. Schematic illustrating that the regions of the brain supporting speech perception depend on the type of acoustic and linguistic processing required, moving from primarily superior temporal regions for noise to an extended network of temporal, frontal, and parietal regions for more complex speech (from Peelle, 2012).

\section{Phoneme processing}

Phonemes are implicitly involved in understanding words and sentences, but can also be studied in isolation. Phonemes require processing an acoustically complex stimulus that can be mapped to learned representations and thus reflect both auditory processing and memory, shaped by a listener's language experience.

A number of neuroimaging studies have investigated the brain regions supporting phoneme processing. Rimol and colleagues (2005) used fMRI to examine activity for consonantvowel (CV) syllables and stop consonants, compared to a noise control condition. They found increased activation for both consonants and syllables relative to noise in posterior superior temporal sulcus (STS) and middle temporal gyrus (MTG) bilaterally, with some suggestion of greater activity in the left hemisphere (see also Obleser et al., 2007). In another fMRI study, Liebenthal and colleagues (2005) had listeners perform a two-alternative forced choice discrimination task on either phonemes or carefully-matched nonphoneme control sounds. The 
control sounds were created by spectrally inverting the first formant (F1) of the phonemic stimuli, and were thus identical in duration and acoustic complexity, but did not involve phonemic representations. The authors found increased activity for the phonemes compared to nonphonemes in the left STS (see also Blumstein et al., 2005). It is important to emphasize that the activity seen for phonemes, in STS, is typically smaller in extent and more ventral than activity in auditory regions evoked by nonspeech stimuli (Hall et al., 2002). This is consistent with a computational hierarchy for auditory processing in which learned representations (phonemes) are not stored in primary auditory cortex, but in later regions, presumably allowing for more flexibility in representing relationships between low-level features (Chang et al., 2010). Intercranial recordings from humans have shown that activity in posteriolateral temporal cortex can distinguish between different categories (Mesgarani et al., 2014, Nourski et al., 2014, Steinschneider et al., 2011).

Roles for both the left STS and left supramarginal gyrus in phoneme processing were also suggested by Jacquemot and colleagues (2003), who studied phonological processing in Japanese and French to dissociate acoustic properties (which were identical regardless of the native language of the listener) from phonological properties (which differed based on a listener's native language). They had listeners perform a discrimination task in which three pseudowords were presented: the first two identical, the third either matching or mismatching. The differences could be acoustic or phonological depending on the native language of the participant, allowing the authors to isolate activity due to phonological processing. Phonological change conditions were associated with regions of left superior temporal gyrus and left supramarginal gyrus.

Raizada and Poldrack (2007) used fMRI to study categorical processing, with a special focus on stimuli that bridged category boundaries. They found activity in several regions, most notably the left supramarginal gyrus, related to perceptual category boundaries. They interpret this finding as reflecting neural amplification of perceptually-important stimulus changes. In a habituation paradigm, Joanisse and colleagues (2007) also found both STG and inferior parietal cortex (near the supramarginal gyrus) responding to "deviant" phonemes, suggesting a role in novelty detection.

Finally, regions of left IFG have also been implicated in phoneme perception, including invariance to exemplars from the same phonetic category (Myers et al., 2009), multivariate responses that can predict categorical boundaries (Lee et al., 2012), and perceptual restoration of phonemes (Leonard et al., 2016). Rogers and Davis (2017) created continua of words (e.g., blade-glade), pseudowords (e.g., blem-glem), and word-pseudoword pairs (e.g., bone-ghone). They found increased responses in left IFG for real word conditions with high phonetic ambiguity, suggesting the left IFG is important for phoneme discrimination, particularly when a decision is required about what has been heard.

Thus, phoneme processing relies on regions of the STS/STG, supramarginal gyrus, and IFG. The specific regions involved likely reflect not only the stimuli, but the nature of the task (for example, passive listening vs. categorical judgments).

\section{Single word processing}

In addition to processing the formant transitions conveying phonemic information, processing single words involves both lexical and semantic representations. ${ }^{1}$ At the lexical level, the

\footnotetext{
${ }^{1}$ In some instances we may develop lexical representations without semantic representations. For example, I could instruct you that "negus" is a real word, without defining it. With training, these lexical representations show wordlike effects (such as competing with similar sounding words) even though they lack a clear conceptual meaning (Davis et al., 2009). In everyday conversation these situations are rare, but still may occur (for example, someone might learn to recognize a new word they hear in conversation before learning its meaning).
} 
appropriate word must be selected, taking into consideration the range of possible alternativesi.e., all possible words - and acoustic and linguistic contextual cues which may make some words more likely than others.

Some of the earliest neuroimaging studies of speech processing showed bilateral temporal lobe activation when participants heard single words (Price et al., 1996, Price et al., 1992), a result that has been routinely replicated using a variety of different paradigms. In an fMRI study of word processing, Binder and colleagues (2000) compared activity for single words to a variety of control conditions including broadband noise, pure tones, nonwords, and reversed speech. They found that all stimuli elicited robust activation in bilateral superior temporal gyri. Smaller regions of bilateral superior temporal gyri showed a hierarchical progression, with responses to words being greater than to tones, which in turn were greater than to broadband noise. These findings support key roles for the STS and MTG in word processing, confirmed by many other studies using spoken words (Eckert et al., 2008, Bozic et al., 2010, Fonteneau et al., 2015, Sohoglu et al., 2012, Specht and Reul, 2003, Burton and Small, 2006).

One important point worth emphasizing is that although traditional neuroanatomical models of language focus on the left hemisphere, there is compelling converging evidence that both left and right temporal cortices support single word processing. First, as already noted, neuroimaging studies routinely show activation in both left and right temporal cortex. Perhaps more convincingly, patients undergoing a Wada procedure (anesthetizing one hemisphere for language lateralization) are able to perform single word processing tasks with only their right hemisphere (McGlone, 1984). For example, Hickok and colleagues (2008) studied a group of patients who underwent the Wada procedure during presurgical evaluation for medically uncontrolled epilepsy. Participants were presented with auditory words, and were instructed to select which of four alternative pictures best matched the word. Foils could differ from the target word phonemically or semantically, allowing the authors to examine different types of errors. Although more errors were made during left hemisphere anesthesia than for right hemisphere anesthesia, most were semantic errors. Most importantly, even under conditions of left hemisphere anesthesia, word perception performance was well above chance levels. This finding would not be expected if word processing were conducted exclusively by left hemisphere regions. Of course, lateralization effects may well be a matter of degree. Additional research that quantitatively compare processing in left and right hemispheres to single words will be important in resolving this question.

Although the main brain regions involved in word level processing appear centered in bilateral superior temporal cortex, factors such as word frequency, the number of competitors, the conceptual meaning of a word, and other psycholinguistic considerations can all affect the brain networks involved, some of which I briefly touch on in the sections below.

\section{Lexical competition}

Most contemporary models of speech recognition operate in an activation-competition framework in which words whose stored representations are consistent with the incoming sensory input are considered possible candidates (Marslen-Wilson and Tyler, 1980, Norris and McQueen, 2008, Luce and Pisoni, 1998). Words that are acoustically similar to the target word make the task of selecting the correct word more difficult, particularly if the sensory input is degraded (for example, due to background noise). Thus, even words that are correctly perceived can differ in the amount of competition resolved during perception. Although behavioral effects of lexical competition have been demonstrated for some time, only recently have the neural networks required to deal with increased competition been investigated.

Zhuang and colleagues (2014) presented listeners with nonwords, constructed such that, at the stimulus onset, an item could potentially be a word. The point at which the item became a 
nonword could occur early or late in the stimulus. The items also varied in their initial cohort size (related to lexical competition) and cohort dropout rate (related to lexical selection). They observed a cluster in left MTG and superior temporal gyrus (STG) that showed increasing activity for items with late nonword points, consistent with the hypothesis that increasing matching results in greater processing demands in left hemisphere regions associated with lexical-semantic processing. Within the late nonword items, the authors looked for parametric effects of cohort competition and cohort selection. Competition effects were seen in bilateral ventral IFG (pars orbitalis), whereas selection effects were in more dorsal IFG (pars triangularis). These findings are supported by an MEG study from Kocagoncu and colleagues (2017) that showed effects of lexical competition occur relatively early after word onset in left STS/MTG followed by left IFG.

A particularly clever approach to lexical competition is to teach listeners new words that alter the competitors of existing items in the lexicon. For example, "cathedral" has few competitors; teaching participants that "cathedruke" is a word thus increases the amount of competition substantially. Interestingly, new words do not act as competitors until after asleep (Dumay and Gaskell, 2007), presumably due to sleep-related consolidation processes (Davis and Gaskell, 2009). Increased competition effects related to word learning are seen in auditory cortex and hippocampus (Gagnepain et al., 2012, Davis et al., 2009), suggesting effects of consolidation on the representation of acoustic word forms.

\section{Semantic representations}

Although still an area of active debate, many current approaches to semantic memory conform to a "hub and spoke" arrangement (Patterson et al., 2007, Reilly et al., 2016b). Evidence for modality-specific representations comes in part from a long history of category-specific semantic memory deficits that suggest representations for different categories (for example, animals vs. manufactured objects) are stored in anatomically-separable locations in the brain (McCarthy and Warrington, 2016) (that is, if there were no anatomical distinctions between different categories, it would be impossible to impair knowledge about one category but not another following brain damage). In addition, studies suggest activity in modality-specific sensory and motor regions corresponding to specific types of information (for example, visual areas showing more activity for concepts relying on visual information) (Reilly et al., 2016a). Bonner and colleagues (2013) presented participants with written words in a lexical decision task. The words varied in their sensory-motor associations, being primarily visual (e.g., apple), primarily auditory (e.g., thunder), primarily motor (e.g., corkscrew), or abstract concepts (e.g., justice). The authors found increased activity (relative to nonwords) in the angular gyrus for all word categories. Provocatively, there were also suggestions of increases in modality specific regions (for example, words with high auditory associations were associated with increased activity in auditory association cortex). These findings are in agreement with reports that patients with neurodegenerative disease who have gray matter atrophy in auditory association cortex perform more poorly on auditory concepts than other modalities (Bonner and Grossman, 2012). Thus, the nature of the concepts associated with individual words alters the brain regions involved in word comprehension.

Complementing evidence for distributed semantic representations is a rich history on amodal "hubs" that represent information from multiple modalities (or function to bind heteromodal information together). Traditionally, some of the strongest evidence comes from patients with semantic dementia (also referred to as the semantic variant of primary progressive aphasia, or svPPA). The most common areas of damage in svPPA are the left temporal pole and lateral anterior temporal lobe, extending back into the fusiform gyrus (Mummery et al., 2000, Gorno-Tempini et al., 2004). Patients with svPPA show impaired representation across semantic 
category, regardless of the modality of the input or output (Bozeat et al., 2000, Bozeat et al., 2003), suggesting these regions of left temporal cortex play a critical role in semantic memory. Complimentary evidence from fMRI implicates the angular gyrus as a second semantic hub: it is commonly activated in studies of semantic memory (Binder et al., 2009), responds to combinations of word concepts (Price et al., 2015, Graves et al., 2010), and gray matter volume in the angular gyrus relates to word learning (Lee et al., 2007).

Finally, it is worth noting the involvement of left IFG in semantic processing, particularly when decisions need to be made about a semantic property or category. For example, when selecting a target item from among a group of competing alternatives (Thompson-Schill et al., 1997) or making semantic judgments (Whitney et al., 2011).

Thus, semantic representation relies on both modality-specific and amodal regions, with increased involvement of left IFG to resolve competition.

\section{Sentence processing}

In addition to the phonemic, lexical, and semantic processing required for understanding individual words, understanding sentences requires an appreciation for the conceptual and syntactic constraints that tie multiple words together. We have learned a great deal about the major brain networks involved in processing intelligible speech by observing the brain regions that are more active when listeners hear intelligible sentences compared to unintelligible control stimuli. One of the earliest and most influential demonstrations was conducted by Scott and colleagues (2000), who used PET to measure neural responses to intelligible sentences compared to unintelligible spectrally-rotated sentences. They found regions of left temporal cortex, notably lateral anterior temporal lobe, showed a preferential response to intelligible speech. More recent investigations using similar stimuli have replicated (and extended) the main findings (Evans, 2017).

In a landmark study of auditory sentence processing, Davis and Johnsrude (2003) took a parametric approach to studying intelligibility. They used AMRI to monitor neural activity while participants listened to sentences that were presented at varying levels of intelligibility that had been arrived at through different forms of acoustic degradation (speech in noise, alternated speech, noise vocoded speech). This design thus helped identify regions that responded parametrically to speech intelligibility, but also the degree to which such regions were impacted by speech acoustics. They found that activity in bilateral superior temporal cortex and left ventral inferior frontal gyrus correlated with speech intelligibility. In auditory cortex and nearby temporal lobe regions, these responses differed based on the type of acoustic manipulation performed, but in regions further removed-posterior and anterior to auditory cortex in the temporal lobe, and inferior frontal gyrus - responses were comparable regardless of the acoustic manipulation. These findings support a hierarchical organization to sentence processing in which information is transformed to more abstract representations as it travels away from auditory cortex along both the dorsal and ventral stream (Peelle et al., 2010a).

Given a general understanding of the main regions involved in understanding spoken sentences, we can again ask what functions may be supported by each of the areas, starting with primary auditory cortex. Although bilateral auditory cortex is naturally involved in low-level acoustic processing, recent studies have begun to identify features that have particular importance. One influential line of work focuses on how ongoing oscillatory activity in auditory cortex locks on to the acoustic envelope of connected speech (Giraud and Poeppel, 2012, Peelle and Davis, 2012). This research was inspired in part by studies using electrophysiology to examine auditory cortex responses to rhythmic stimuli in monkeys, as animal work shows phase locking to regular auditory stimuli (Lakatos et al., 2005). Human work using EEG and MEG is 
consistent with these observations: the phase of neural responses in auditory cortex discriminates between individual sentences (Luo and Poeppel, 2007). Oscillatory entrainment to the speech signal is enhanced for intelligible speech relative to less intelligible control stimuli (Peelle et al., 2013), suggesting phase locking may play a role in language comprehension beyond acoustic processing (Ding et al., 2016).

Phase-locked responses reflect top-down attention (Lakatos et al., 2013, Lakatos et al., 2008), and during multi-talker listening more strongly reflect the target talker (Rimmele et al., 2015, Kerlin et al., 2010, Mesgarani and Chang, 2012, Zion Golumbic et al., 2013). Because phase-locked oscillations form a nested hierarchy (Gross et al., 2013), linking oscillations to the speech signal at one level (for example, 4-7 Hz) can potentially affect processing at many other timescales (Canolty and Knight, 2010, Jensen and Colgin, 2007), which may be important in breaking the continuous speech signal into manageable computational units (Ghitza, 2011). Thus, oscillatory activity in auditory cortex is well-suited to contribute to the comprehension of connected speech (Peelle and Davis, 2012).

Moving beyond the temporal lobe, left inferior frontal gyrus is often active during sentence processing (Adank, 2012). Because left inferior frontal activity it not consistently observed for perception of single words or phonemes, a reasonable conclusion is that it reflects some aspect of sentence processing. One suggestion, which I cover in more detail below, is that left inferior frontal gyrus (sometimes including "Broca's Area") plays a specific role in syntactic processing (Grodzinsky and Santi, 2008). However, left inferior frontal gyrus might support other processes during sentence comprehension that are not syntax-specific, including processes related to semantic integration (Hagoort, 2013), phrase building, or domain-general selection (Thompson-Schill et al., 1997). Thus, although there is widespread agreement that the left inferior frontal gyrus is frequently active during sentence comprehension, the best way to characterize the processes engaged is still actively debated (Friederici and Gierhan, 2013, Fedorenko et al., 2012, Rogalsky and Hickok, 2011).

Although these studies help establish the core regions supporting intelligible speech processing, it is important to realize that everyday sentence comprehension requires solving a variety of linguistic challenges, and that doing so involves additional brain regions. Below I examine two illustrative examples: syntactic complexity, and semantic ambiguity.

\section{Syntactic complexity}

To correctly understand the meaning of a sentence, listeners must not only identify individual words but also determine the syntactic relationships between the words. For example, consider the following two sentences:

1. Kings that help queens are nice.

2. Kings that queens help are nice.

The words are identical, but changing their order alters the meaning of the sentence. In the first, kings are doing the helping, whereas in the second queens are doing the helping. There are many ways to change the syntactic processing demands of a sentence, which might rely on shared or separable neural systems. What regions are implicated in syntactic processing?

For several decades, the left inferior frontal gyrus has been known to play an important role in syntactic processing. Although patients with Broca's aphasia have generally preserved language comprehension (i.e., production difficulties are a defining feature), they frequently have difficulty comprehending syntactically complex sentences (Love et al., 2008, Tyler et al., 2011, Papoutsi et al., 2011, Grodzinsky, 2000, Swinney and Zurif, 1995). This observation has been replicated in patients with nonfluent primary progressive aphasia (Peelle et al., 2008, Peelle 
et al., 2007), which is also associated with damage to left inferior frontal cortex (Grossman, 2012).

In an fMRI study of spoken sentence processing in healthy adults (Peelle et al., 2010b), we examined activity for short sentences that contained center-embedded clauses that had a subject-relative ("Kings that help queens are nice") or object-relative ("Kings that queens help are nice") construction. Object-relative sentences have greater processing demands and are associated with poorer accuracy, longer response times (Wingfield et al., 2003), and/or increased brain activity (Lee et al., 2016, Peelle et al., 2004). We found syntax-related increases in many regions, most notably left inferior frontal gyrus and dorsolateral prefrontal cortex, but also including middle temporal gyrus and inferior parietal cortex. These findings are in agreement with a number of studies of both auditory and visual sentence processing implicating left IFG in syntactic complexity (Hassanpour et al., 2015, Rodd et al., 2010, Tyler et al., 2010) and suggest left IFG plays a role in processing syntactically complex sentences.

\section{Semantic ambiguity}

Another frequently-encountered challenge during sentence processing is that many words have multiple meanings, and the correct meaning must be inferred by the listener based on context. For example, the word "bark" can refer to the outer covering of a tree or the sound a dog makes, and in isolation its meaning is thus ambiguous. However, listeners have no difficulty understanding a sentence such as "Jamie was scared of the loud bark". Although we often subjectively experience this process of disambiguation as automatic, in fact it is not: When listeners hear sentences with ambiguous words, there are reliable increases in activity in left hemisphere regions associated with semantic processing, including fusiform gyrus, middle temporal gyrus, and inferior frontal gyrus (Rodd et al., 2005, Rodd et al., 2012, Zempleni et al., 2007, Rodd et al., 2010).

Using multivariate techniques, Musz and Thompson-Schill (2017) investigate processing of homonyms that varied in the degree of meaning dominance in written language. For example, a word like "pen" has a highly dominant meaning (a writing implement), relative to other meanings (such as an enclosure for animals). A word like "pitcher", on the other hand, has several meanings that are approximately equal in dominance (a container for liquid, or a position on a baseball team). These items were presented in sentences that biased interpretation towards a dominant or subordinate meaning, and subsequently read each word in isolation. The authors found that left IFG showed sensitivity to context (dominant vs. subordinate) and time disambiguating information was available (see also Rodd et al., 2012), and that left ventral anterior temporal lobe further varied in activity in relation to word-by-word variability in meaning dominance.

Finally, semantic disambiguation appears to depend on conscious attention, and neural responses associated with disambiguation disappear in mildly sedated listeners who still show robust cortical responses to acoustic stimulation (Davis et al., 2007), consistent with a reliance on active processing (for example, taking into account the surrounding context).

\section{Spoken narrative comprehension}

Understanding spoken language that spans multiple sentences is not uncommon and occurs during lectures and listening to stories. Neuroimaging studies of spoken narratives are particularly challenging because of the impact of scanner noise, which cannot be avoided using sparse imaging techniques as can be done for shorter stimuli (Edmister et al., 1999, Hall et al., 1999). 
Data from narrative comprehension in quiet comes in part from PET studies. Crinion and colleagues (2003) played short children's stories for participants while measuring brain activity with PET. Compared to reversed speech, listening to the story resulted in stronger activity in bilateral temporal regions, most notably along the middle temporal gyrus, extending to the lateral anterior temporal lobe. It is somewhat surprising that no responses in frontal cortex were observed; this may have been due to either the modest number of participants, or the nature of the materials.

Additional data comes from studies using continuous fMRI scanning, which are informative but must be interpreted in the context of the additional acoustic noise. To investigate temporal dependencies at different time scales, Lerner and colleagues (2011) played participants a 7-minute story in its original form, and temporally scrambled at the level of words, sentences, or paragraphs. They found that the reliability of intersubject correlations varied, with regions near auditory cortex showing strong responses regardless of the temporal window (i.e., driven strongly by word-level processing). Regions further along in the hierarchy, in frontal cortex, showed more reliable responses for longer temporal windows. These analyses suggest not only a role for frontal cortex in narrative comprehension, but that frontal regions are required in particular for understanding the more complex structure (and longer temporal duration) of sentences and paragraphs.

Converging evidence in support of a role for frontal cortex in narrative processing comes from patients with frontotemporal dementia (FTD), a family of neurodegenerative diseases associated with progressive damage in circumscribed brain regions (Peelle and Grossman, 2008). Patients with behavioral variant FTD (bvFTD) are of particular interest because language impairments are not a primary symptom, and they have damage to large regions of bilateral frontal cortex. When trying to tell a short story, patients with bvFTD have difficulty organizing the story and are more likely to miss the main point of the story (Ash et al., 2006). This behavior contrasts with FTD patients diagnosed with primary progressive aphasias, who have significant difficulties with language processing but not in these narrative-level operations. Similar narrative difficulties are seen in patients with amyotrophic lateral sclerosis, also related to damage in prefrontal cortex (Ash et al., 2014).

Thus, the brain networks involved in understanding a spoken narrative largely overlap the core sentence processing network. However, regions of frontal cortex may play an additional important role in maintaining thematic relationships over long time scales.

\section{Neural systems supporting audiovisual speech perception}

My focus so far has been on the brain systems involved in understanding auditory speech. However, in everyday conversation we can frequently see the speaker's face, providing an additional source of speech information. Speech perception, particularly in noise, is almost always more accurate when listeners can both hear and see a talker compared with listening alone (Erber, 1975, Sumby and Pollack, 1954). This clear behavioral finding raises challenges for neuroscience models of speech processing: how does information that necessarily enters the brain through different sensory receptors become integrated to form a single percept?

There are three anatomical regions which have been the focus of the neural basis for multisensory speech understanding, reflecting differing theoretical views of the underlying processes. The first is primary auditory cortex, which may represent temporal properties in connected speech (i.e., the amplitude envelope). The second is a heteromodal region of lateral posterior temporal cortex that are well-positioned to perform multisensory integration. The third is motor or premotor cortex as a way to retrieve articulatory representations. These mechanisms 
are not mutually exclusive, but have been suggested based on results from different experimental paradigms and theoretical motivations. I discuss each in turn below.

\section{Temporal predictions in auditory cortex}

Evidence from electrophysiology studies in nonhuman primates shows that oscillations in auditory cortex entrain to periodic stimuli, creating systematic fluctuations in population neural excitability (Lakatos et al., 2005). Importantly, the phase of neural oscillations in the $\sim 3-7 \mathrm{~Hz}$ range have also been shown to entrain to human speech (Luo and Poeppel, 2007), with stronger entrainment for intelligible speech (Peelle et al., 2013). The entrainment of cortical oscillations to the acoustic speech envelope suggests a mechanistic role in auditory speech perception (Peelle and Davis, 2012) and a mechanism to affect hierarchical processing through nested oscillatory activity (Gross et al., 2013). Such a role is supported by the effects of attention on phase-locked oscillations in multitalker situations (Zion Golumbic et al., 2013), understanding speech in background noise (Ding and Simon, 2013), and phoneme-level representations (Di Liberto et al., 2015).

More relevant for audiovisual speech processing are the multimodal effects observed in auditory cortex. Haptic stimulation can reset auditory oscillations, increasing sensitivity to motor inputs that follow (Lakatos et al., 2007). These findings lend support to the hypothesis that cortical oscillations can act as instruments of attentional selection, biasing perception to be more sensitive to behaviorally relevant inputs (Lakatos et al., 2013, Schroeder and Lakatos, 2009). Together these observations suggest that oscillatory entrainment may play an important role in audiovisual speech perception (Schroeder et al., 2008).

Luo and colleagues (2010) played audiovisual movies to participants while recording brain activity with MEG. As might be expected, they found oscillations in primary sensory cortices tracked modality-specific information (i.e., oscillations in auditory cortex tracked acoustic information in the movies, and oscillations in visual cortex tracked visual information in the movies). Critically, however, they also found that visual information modulated acoustic entrainment in auditory cortex. A related finding was reported by Crosse and colleagues (2015), who found that visual information improved representation of the acoustic speech envelope in auditory cortex. This cross-modal modulation suggests that human speech perception conforms to principles of multisensory integration identified in animal studies.

What information might be provided by the visual stream, reflected in these oscillatory effects? One possibility is information regarding the acoustic envelope, which is typically strongly correlated with mouth opening (Chandrasekaran et al., 2009). Although envelope information may not be particularly informative regarding specific articulatory cues, it provides overall information about speech rhythm, and may therefore guide listeners towards extracting information from relatively more informative temporal windows.

It is worth noting that some, though not all, fMRI studies of visual or audiovisual speech perception have found changes in activity in auditory cortex associated with visual speech information (Calvert et al., 1997). Whether there is a link between altered oscillatory activity and fMRI activity in primary auditory cortex is unclear; however, both clearly implicate auditory cortex in audiovisual speech processing.

Although amplitude information may be useful in understanding connected speech, it likely plays less of a role in single words, as listeners have less opportunity to entrain to a talker's speech. And in all cases, the amplitude envelope does not provide a great deal of information to constrain phoneme perception, suggesting the need for complementary processes (Peelle and Sommers, 2015). Two primary candidates for these are posterior STS and premotor cortex, which I discuss below. 


\section{Posterior superior temporal sulcus as a site of multisensory integration}

Posterior STS is a region of heteromodal association cortex with anatomical connections to both auditory and visual cortex (Seltzer et al., 1996). Although not consistently active in studies of auditory-only speech perception, posterior STS routinely appears in fMRI studies of audiovisual speech perception, particularly in studies using McGurk stimuli. The well-known McGurk effect (McGurk and MacDonald, 1976) provides a compelling demonstration of multisensory integration: When an auditory stimulus (e.g., /ba/) is presented with the face of a speaker articulating a different syllable (e.g., /ga/), listeners often perceive an illusory percept distinct from both sources (e.g., /da/). In many fMRI studies using McGurk stimuli, incongruent trials (i.e., trials eliciting a McGurk effect, and thus demonstrating multisensory integration) are compared to congruent trials. This comparison frequently reveals increased activity in left posterior STS (Jones and Callan, 2003, Sekiyama et al., 2003, Skipper et al., 2007, Matchin et al., 2014), suggesting this region plays a critical role for multisensory integration (Beauchamp, 2005, Desimone and Gross, 1979, Beauchamp et al., 2004).

In one particularly elegant study, Nath and Beauchamp (2011) presented listeners with McGurk stimuli that varied in the perceptual clarity of the auditory portion (by adding background noise) or the visual portion (by spatial blurring). The authors assessed functional connectivity between auditory and visual cortex and posterior STS, and found that functional connectivity increased as a function of the clearer input. That is, when the visual input was blurred, functional connectivity between posterior STS and auditory cortex increased, potentially reflecting a reweighting of multisensory input based on the reliability of the information provided (Ernst and Banks, 2002). Complementary evidence for this conclusion comes from a TMS study in which processing in posterior STS was disrupted, resulting in a disruption of the McGurk effect (Beauchamp et al., 2010).

It should be noted that despite the intuitive appeal of McGurk-type stimuli for studying audiovisual speech perception, there are reasons to question whether the same processes operate during natural speech perception (Alsius et al., 2017). For example, McGurk stimuli require reconciling conflicting auditory and visual cues, which does not happen in natural speech, and at least in some studies individual differences in McGurk susceptibility do not relate to a listener's performance during audiovisual sentence perception (Van Engen et al., 2017).

\section{Left frontal cortex as a pathway for motor representations to affect perception}

Activity in left premotor cortex is commonly observed during neuroimaging studies of speech perception (for example, listening to spoken words) (Binder et al., 2000), and stimulating motor cortex during perception has been suggested to influence speech perception (Schomers et al., 2015). Although the observation of premotor activity likely depends on factors such as the comparison condition or acoustic environment (for example, quiet vs. background noise), its presence has suggested to many researchers the idea that premotor cortex may play a role in speech perception. ${ }^{2}$ Here I will focus specifically on the potential role for motor representations in understanding audiovisual speech.

Fridriksson and colleagues (2008) used fMRI to investigate neural activation when participants performed a discrimination task on visual speech stimuli (without auditory information). They found increased activation in bilateral STG, left IFG, and left premotor cortex for visual speech compared to a visual nonspeech control condition. Furthermore, activity in left

\footnotetext{
${ }^{2}$ It is worth noting some superficial similarities between these observations and the influential motor theory of speech perception (Liberman et al., 1967, Liberman and Mattingly, 1985), particularly in the context of mirror neurons. However, the modern cognitive neuroscience approach differs in important ways (Lotto et al., 2009, Rogalsky et al., 2011), and is my focus here.
} 
IFG and premotor cortex increased when the visual speech was degraded (by decreasing the frame rate), an effect absent for the nonspeech stimuli, suggesting a role for these regions of left frontal cortex in visual speech perception. Consistent with these results, Okada and Hickok (2009) presented participants with visual-only clips of single phonemes, and observed activation in bilateral superior temporal gyrus, left IFG, and left premotor cortex.

Additional evidence supporting a role for motor representations in audiovisual speech processing comes from a role for visual speech in speech production. In one set of relevant studies, Fridriksson and colleagues (Fridriksson et al., 2012, Fridriksson et al., 2015) studied the degree to which viewing speech facilitated speech production in patients with nonfluent aphasia. Patients produced a greater variety of words when viewing audiovisual speech compared to auditory speech alone, and showed benefit to speech fluency with training.

In an fMRI study, Venezia and colleagues (2016) used a covert repetition paradigm with consonant-vowel (CV) syllables (e.g., /ba/) to test whether using visual-only or audiovisual stimuli to cue repetition recruited different networks compared to auditory-only input. Activity was observed both in posterior STS and premotor cortex. Importantly, speech motor regions were more active when the stimulus included visual speech, despite identical rehearsal requirements. These results suggest that processing visual speech entailed recruitment of a specific network of sensorimotor brain regions. If perceiving visual speech indeed involves motor regions, it would provide a straightforward mechanism to explain the speech entrainment results mentioned earlier.

Finally, there are results linking motor representations to speech-related cortical oscillations introduced previously. Park and colleagues (2016) used MEG to measure oscillatory activity while participants viewed audiovisual speech clips (narrative speech). They identified a significant coherence between oscillatory activity and visual cortex and a speaker's lip movements. More interestingly, they also observed significant coherence between a speaker's lip movements and oscillations in a listener's left motor cortex that was positively correlated with comprehension accuracy.

In summary, it is unlikely that motor speech representations are necessary for either auditory-only or audiovisual speech perception, as stroke patients with damage to these regions are able to perceive speech (Rogalsky et al., 2011). However, converging evidence points towards at least a supporting role for motor regions, which may contribute to the integration of multisensory information during audiovisual speech perception.

\section{How acoustic challenge affects the brain networks supporting speech understanding}

In everyday experience, we often listen to speech in less-than-ideal acoustic circumstances, including in the presence of background noise, competing talkers, foreign accents, or hearing loss (Mattys et al., 2012). There is now considerable evidence that acoustic challenges of this sort change the cognitive processes listeners engage during speech understanding (Peelle, 2018), further modulated by the motivation a listener has to understand what they are hearing (PichoraFuller et al., 2016).

Beyond the core speech regions already discussed, listening to acoustically degraded speech is routinely associated with increased brain activity, commonly in regions of frontal cortex. Davis and Johnsrude (2003) presented listeners with spoken sentences that were acoustically degraded in three ways: with background noise, through noise vocoding (Shannon et al., 1995), or as interrupted speech. They found areas of left prefrontal and premotor cortex that showed increased activity for degraded speech relative to clear speech, consistent with an increase in reliance on executive processes to successfully extract meaning from the acoustic 
signal. Increased frontal activity has also been seen to correlate with variability within the range of normal hearing in adults with clinically-normal hearing (Lee et al., 2018).

A particularly relevant network for understanding degraded speech is the cinguloopercular network, an executive attention network associated with task maintenance and error monitoring (Dosenbach et al., 2008, Neta et al., 2015, Power and Petersen, 2013). As with other tasks, during speech processing activity in the cingulo-opercular network is elevated following incorrect trials (i.e., incorrect perception of words in noise) (Wild et al., 2012, Erb et al., 2013, Eckert et al., 2009). Interestingly, trial-by-trial variations in activity in the cingulo-opercular network relate to memory for specific items (Vaden Jr. et al., 2017) and the intelligibility of the following word (Vaden Jr. et al., 2013), both suggesting a functional role for the cinguloopercular network and speech intelligibility.

In addition to background noise, one common example of difficult speech processing comes from listening to speech in a non-native accent. Although there is ample behavioral evidence that this type of accented speech can be more difficult to process (Van Engen and Peelle, 2014), there is less evidence regarding the neural underpinnings of accented speech processing (Adank et al., 2015). In one study, Adank and colleagues (2012) examined neural processing for native speech and a novel accent. In contrast to speech in noise-which was associated with increased activity in the cingulo-opercular network - accented speech was associated with increased activity in the left anterior lateral temporal cortex. However, much remains unknown about the factors that affect

It is clear that acoustic challenge of many sorts drastically changes the cognitive resources listeners require to understand sentences. In this context it is worth pointing out that fMRI scanning is associated with significant acoustic noise, in the rage of 80-120 dBA or higher (Price et al., 2001, Ravicz et al., 2000, Foster et al., 2000). Although earplugs can help reduce the effects, hearing protection cannot fully block external sound, nor can it stop conduction through a listener's bones. Thus, when using fMRI to study speech processing, special sequences are often used to minimize scanner noise, and the acoustic scanning environment must always be considered when interpreting results (Peelle, 2014).

\section{Summary}

The brain networks required to understand human speech are anatomically widely distributed, and differ as a function of the specific acoustic and linguistic demands of a stimulus. Bilateral superior temporal cortex is engaged in phoneme and word processing, supplemented by left inferior frontal gyrus during sentence comprehension. However, this core speech network is flexible, and during various types of linguistic or acoustic challenge, additional regions are frequently recruited, most notably executive attention networks. This neural flexibility highlights the importance of cognitive contributions to the sending and receiving end of the speech chain. 


\section{Acknowledgments}

This work was supported by NIH grants R01DC014281, R21DC015884, and the Dana

Foundation. I am grateful to Aahana Bajracharya and Mike Jones for helpful comments on this chapter. 


\section{References}

ADANK, P. 2012. Design choices in imaging speech comprehension: An activation likelihood estimation (ALE) meta-analysis. NeuroImage, 63, 1601-1613.

ADANK, P., DAVIS, M. H. \& HAGOORT, P. 2012. Neural dissociation in processing noise and accent in spoken language comprehension. Neuropsychologia, 50, 77-84.

ADANK, P., NUTTALL, H. E., BANKS, B. \& KENNEDY-HIGGINS, D. 2015. Neural bases of accented speech perception. Front Hum Neurosci, 9, 558.

ALSIUS, A., PARÉ, M. \& MUNHALL, K. G. 2017. Forty Years After Hearing Lips and Seeing Voices: the McGurk Effect Revisited. Multisensory Research.

ASH, S., MENAGED, A., OLM, C., MCMILLAN, C. T., BOLLER, A., IRWIN, D. J., MCCLUSKEY, L., ELMAN, L. \& GROSSMAN, M. 2014. Narrative discourse deficits in amyotrophic lateral sclerosis. Neurology, 83, 520-528.

ASH, S., MOORE, P., ANTANI, S., MCCAWLEY, G., WORK, M. \& GROSSMAN, M. 2006. Trying to tell a tale: Discourse impairments in progressive aphasia and frontotemporal dementia. Neurology, 66, 1405-1413.

BEAUCHAMP, M. S. 2005. See me, hear me, touch me: multisensory integration in lateral occipital-temporal cortex. Current Opinion in Neurobiology, 15, 145-153.

BEAUCHAMP, M. S., LEE, K. E., ARGALL, B. D. \& MARTIN, A. 2004. Integration of auditory and visual information about objects in superior temporal sulcus. Neuron, 41, 809-823.

BEAUCHAMP, M. S., NATH, A. R. \& PASALAR, S. 2010. fMRI-guided transcranial magnetic stimulation reveals that the superior temporal sulcus is a cortical locus of the McGurk effect. Journal of Neuroscience, 30, 2414-2417.

BINDER, J. R., DESAI, R. H., GRAVES, W. W. \& CONANT, L. L. 2009. Where is the semantic system? A critical review and meta-analysis of 120 functional neuroimaging studies. Cerebral Cortex, 19, 2767-2796.

BINDER, J. R., FROST, J. A., HAMMEKE, T. A., BELlGOWAN, P. S., SPRINGER, J. A., KAUFMAN, J. N. \& POSSING, E. T. 2000. Human temporal lobe activation by speech and nonspeech sounds. Cerebral Cortex, 10, 512-528.

BLUMSTEIN, S. E., MYERS, E. B. \& RISSMAN, J. 2005. The perception of voice onset time: an fMRI investigation of phonetic category structure. J Cogn Neurosci, 17, 1353-66.

BONNER, M. F. \& GROSSMAN, M. 2012. Gray matter density of auditory association cortex relates to knowledge of sound concepts in primary progressive aphasia. Journal of Neuroscience, 32, 7986-7991.

BONNER, M. F., PEELLE, J. E., COOK, P. A. \& GROSSMAN, M. 2013. Heteromodal conceptual processing in the angular gyrus. NeuroImage, 71, 175-186.

BOZEAT, S., LAMBON RALPH, M. A., PATTERSON, K., GARRARD, P. \& HODGES, J. R. 2000. Non-verbal semantic impairment in semantic dementia. Neuropsychologia, 38, 1207-1215.

BOZEAT, S., RALPH, M. A., GRAHAM, K. S., PATTERSON, K., WILKIN, H., ROWLAND, J., ROGERS, T. T. \& HODGES, J. R. 2003. A duck with four legs: Investigating the structure of conceptual knowledge using picture drawing in semantic dementia. Cogn Neuropsychol, 20, 27-47.

BOZIC, M., TYLER, L. K., IVES, D. T., RANDALL, B. \& MARSLEN-WILSON, W. D. 2010. Bihemispheric foundations for human speech comprehension. Proceedings of the National Academy of Science, 107, 17439-17444. 
BURTON, M. W. \& SMALL, S. L. 2006. Functional neuroanatomy of segmenting speech and nonspeech. Cortex, 42, 644-51.

CALVERT, G. A., BULLMORE, E. T., BRAMMER, M. J., CAMPBELL, R., WILLIAMS, S. C. R., MCGUIRE, P. K., WOODRUFF, P. W. R., IVERSEN, S. D. \& DAVID, A. S. 1997. Activation of auditory cortex during silent lipreading. Science, 276, 593-596.

CANOLTY, R. T. \& KNIGHT, R. T. 2010. The functional role of cross-frequency coupling. Trends in Cognitive Sciences, 14, 506-515.

CHANDRASEKARAN, C., TRUBANOVA, A., STILLITTANO, S., CAPLIER, A. \& GHAZANFAR, A. A. 2009. The natural statistics of audiovisual speech. PLoS Computational Biology, 5, e1000436.

CHANG, E. F., RIEGER, J. W., JOHNSON, K., BERGER, M. S., BARBARO, N. M. \& KNIGHT, R. T. 2010. Categorical speech representation in human superior temporal gyrus. Nat Neurosci, 13, 1428-32.

CRINION, J. T., LAMBON RALPH, M. A., WARBURTON, E. A., HOWARD, D. \& WISE, R. J. S. 2003. Temporal lobe regions engaged during normal speech comprehension. Brain, 126, 1193-1201.

CROSSE, M. J., BUTLER, J. S. \& LALOR, E. C. 2015. Congruent visual speech enhances cortical entrainment to continuous auditory speech in noise-free conditions. Journal of Neuroscience, 35, 14195-14204.

DAVIS, M. H., COLEMAN, M. R., ABSALOM, A. R., RODD, J. M., JOHNSRUDE, I. S., MATTA, B. F., OWEN, A. M. \& MENON, D. K. 2007. Dissociating speech perception and comprehension at reduced levels of awareness. Proceedings of the National Academy of Science, 104, 16032-16037.

DAVIS, M. H., DI BETTA, A. M., MACDONALD, M. J. E. \& GASKELL, M. G. 2009. Learning and consolidation of novel spoken words. Journal of Cognitive Neuroscience, 21, 803-820.

DAVIS, M. H. \& GASKELL, M. G. 2009. A complementary systems account of word learning: neural and behavioural evidence. Philosophical Transactions of The Royal Society B, 364, 3773-3800.

DAVIS, M. H. \& JOHNSRUDE, I. S. 2003. Hierarchical processing in spoken language comprehension. Journal of Neuroscience, 23, 3423-3431.

DENES, P. B. \& PINSON, E. N. 1993. The Speech Chain: The physics and biology of spoken language, Long Grove, IL, Waveland Press, Inc.

DESIMONE, R. \& GROSS, C. G. 1979. Visual areas in the temporal cortex of the macaque. Brain Res, 178, 363-80.

DI LIBERTO, G. M., O'SULLIVAN, J. A. \& LALOR, E. C. 2015. Low-Frequency Cortical Entrainment to Speech Reflects Phoneme-Level Processing. Curr Biol, 25, 2457-65.

DING, N., MELLONI, L., ZHANG, H., TIAN, X. \& POEPPEL, D. 2016. Cortical tracking of hierarchical linguistic structures in connected speech. Nat Neurosci, 19, 158-64.

DING, N. \& SIMON, J. Z. 2013. Adaptive temporal encoding leads to a background-insensitive cortical reprsentation of speech. Journal of Neuroscience, 33, 5728-5735.

DOSENBACH, N. U. F., FAIR, D. A., COHEN, A. L., SCHLAGGAR, B. L. \& PETERSEN, S. E. 2008. A dual-networks architecture of top-down control. Trends in Cognitive Sciences, 12, 99-105.

DUMAY, N. \& GASKELL, M. G. 2007. Sleep-associated changes in the mental representation of spoken words. Psychol Sci, 18, 35-9. 
ECKERT, M. A., MENON, V., WALCZAK, A., AHLSTROM, J., DENSLOW, S., HORWITZ, A. \& DUBNO, J. R. 2009. At the heart of the ventral attention system: The right anterior insula. Human Brain Mapping, 30, 2530-2541.

ECKERT, M. A., WALCZAK, A., AHLSTROM, J., DENSLOW, S., HORWITZ, A. \& DUBNO, J. R. 2008. Age-related effects on word recognition: Reliance on cognitive control systems with structural declines in speech-responsive cortex. Journal of the Association for Research in Otolaryngology, 9, 252-259.

EDMISTER, W. B., TALAVAGE, T. M., LEDDEN, P. J. \& WEISSKOFF, R. M. 1999. Improved auditory cortex imaging using clustered volume acquisitions. Human Brain Mapping, 7, 89-97.

ERB, J., HENRY, M. J., EISNER, F. \& OBLESER, J. 2013. The brain dynamics of rapid perceptual adaptation to adverse listening conditions. Journal of Neuroscience, 33, 10688-10697.

ERBER, N. P. 1975. Auditory-visual perception of speech. Journal of Speech and Hearing Disorders, 40, 481-492.

ERNST, M. O. \& BANKS, M. S. 2002. Humans integrate visual and haptic information in a statistically optimal fashion. Nature, 415, 429-33.

EVANS, S. 2017. What Has Replication Ever Done for Us? Insights from Neuroimaging of Speech Perception. Front Hum Neurosci, 11, 41.

FEDORENKO, E., DUNCAN, J. \& KANWISHER, N. G. 2012. Language-selective and domain-general regions lie side by side within Broca's area. Current Biology, 22, 20592062.

FONTENEAU, E., BOZIC, M. \& MARSLEN-WILSON, W. D. 2015. Brain Network Connectivity During Language Comprehension: Interacting Linguistic and Perceptual Subsystems. Cereb Cortex, 25, 3962-76.

FOSTER, J. R., HALL, D. A., SUMMERFIELD, A. Q., PALMER, A. R. \& BOWTELL, R. W. 2000. Sound-level measurements and calculations of safe noise dosage during EPI at $3 \mathrm{~T}$. Journal of Magnetic Resonance Imaging, 12, 157-163.

FRIDRIKSSON, J., BASILAKOS, A., HICKOK, G., BONILHA, L. \& RORDEN, C. 2015. Speech entrainment compensates for Broca's area damage. Cortex, 69, 68-75.

FRIDRIKSSON, J., HUBBARD, H. I., HUDSPETH, S. G., HOLLAND, A. L., BONILHA, L., FROMM, D. \& RORDEN, C. 2012. Speech entrainment enables patients with Broca's aphasia to produce fluent speech. Brain, 135, 3815-29.

FRIDRIKSSON, J., MOSS, J., DAVIS, B., BAYLIS, G. C., BONILHA, L. \& RORDEN, C. 2008. Motor speech perception modulates the cortical language areas. NeuroImage, 41, 605-613.

FRIEDERICI, A. D. \& GIERHAN, S. M. E. 2013. The language network. Current Opinion in Neurobiology, 23, 250-254.

GAGNEPAIN, P., HENSON, R. N. \& DAVIS, M. H. 2012. Temporal predictive codes for spoken words in auditory cortex. Current Biology, 22, 615-621.

GHITZA, O. 2011. Linking speech perception and neurophysiology: speech decoding guided by cascaded oscillators locked to the input rhythm. Frontiers in Psychology, 2, 130.

GIRAUD, A.-L. \& POEPPEL, D. 2012. Cortical oscillations and speech processing: Emerging computational principles and operations. Nature Neuroscience, 15, 511-517.

GORNO-TEMPINI, M. L., DRONKERS, N. F., RANKIN, K. P., OGAR, J. M., PHENGRASAMY, L., ROSEN, H. J., JOHNSON, J. K., WEINER, M. W. \& MILLER, B. L. 2004. Cognition and anatomy in three variants of primary progressive aphasia. Annals of Neurology, 55, 335-346. 
GRAVES, W. W., BINDER, J. R., DESAI, R. H., CONANT, L. L. \& SEIDENBERG, M. S. 2010. Neural correlates of implicit and explicit combinatorial semantic processing. Neuroimage, 53, 638-46.

GRIFFITHS, T. D., BUCHEL, C., FRACKOWIAK, R. S. \& PATTERSON, R. D. 1998. Analysis of temporal structure in sound by the human brain. Nature Neuroscience, 1 , 422-427.

GRODZINSKY, Y. 2000. The neurology of syntax: Language use without Broca's area. Behavioral and Brain Sciences, 23, 1-21.

GRODZINSKY, Y. \& SANTI, A. 2008. The battle for Broca's region. Trends Cogn Sci, 12, 47480.

GROSS, J., HOOGENBOOM, N., THUT, G., SCHYNS, P., PANZERI, S., BELIN, P. \& GARROD, S. 2013. Speech rhythms and multiplexed oscillatory sensory coding in the human brain. PLOS Biology, 11, e1001752.

GROSSMAN, M. 2012. The non-fluent/agrammatic variant of primary progressive aphasia. Lancet Neurol, 11, 545-55.

HACKETT, T. A. 2011. Information flow in the auditory cortical network. Hear Res, 271, 133 46.

HACKETT, T. A., STEPNIEWSKA, I. \& KAAS, J. H. 1999. Prefrontal connections of the parabelt auditory cortex in macaque monkeys. Brain Research, 817, 45-58.

HAGOORT, P. 2013. MUC (Memory, Unification, Control) and beyond. Frontiers in Psychology, 12, 416.

HALl, D. A., HAGGARD, M. P., AKEROYD, M. A., PALMER, A. R., SUMMERFIELD, A. Q., ELLIOTT, M. R., GURNEY, E. M. \& BOWTELL, R. W. 1999. "Sparse" temporal sampling in auditory fMRI. Human Brain Mapping, 7, 213-223.

HALL, D. A., JOHNSRUDE, I. S., HAGGARD, M. P., PALMER, A. R., AKEROYD, M. A. \& SUMMERFIELD, A. Q. 2002. Spectral and temporal processing in human auditory cortex. Cereb Cortex, 12, 140-9.

HASSANPOUR, M. S., EGGEBRECHT, A. T., CULVER, J. P. \& PEELLE, J. E. 2015. Mapping cortical responses to speech using high-density diffuse optical tomography. NeuroImage, 117, 319-326.

HICKOK, G., OKADA, K., BARR, W., PA, J., ROGALSKY, C., DONNELLY, K., BARDE, L. \& GRANT, A. 2008. Bilateral capacity for speech sound processing in auditory comprehension: Evidence from Wada procedures. Brain and Language, 107, 179-184.

HICKOK, G. \& POEPPEL, D. 2000. Towards a functional neuroanatomy of speech perception. Trends in Cognitive Sciences, 4, 131-138.

HICKOK, G. \& POEPPEL, D. 2007. The cortical organization of speech processing. Nature Reviews Neuroscience, 8, 393-402.

JACQUEMOT, C., PALLIER, C., LEBIHAN, D., DEHAENE, S. \& DUPOUX, E. 2003. Phonological grammar shapes the auditory cortex: A functional magnetic resonance imaging study. Journal of Neuroscience, 23, 9541-9546.

JENSEN, O. \& COLGIN, L. L. 2007. Cross-frequency coupling between neuronal oscillations. Trends in Cognitive Sciences, 11, 267-269.

JOANISSE, M. F., ZEVIN, J. D. \& MCCANDLISS, B. D. 2007. Brain mechanisms implicated in the preattentive categorization of speech sounds revealed using FMRI and a shortinterval habituation trial paradigm. Cereb Cortex, 17, 2084-93.

JONES, J. A. \& CALLAN, D. E. 2003. Brain activity during audiovisual speech perception: an fMRI study of the McGurk effect. Neuroreport, 14, 1129-33. 
KAAS, J. H. \& HACKETT, T. A. 2000. Subdivisions of auditory cortex and processing streams in primates. Proceedings of the National Academy of Sciences, 97, 11793-11799.

KAAS, J. H., HACKETT, T. A. \& TRAMO, M. J. 1999. Auditory processing in primate cerebral cortex. Current Opinion in Neurobiology, 9, 164-170.

KERLIN, J. R., SHAHIN, A. J. \& MILLER, L. M. 2010. Attentional gain control of ongoing cortical speech representations in a "cocktail party". Journal of Neuroscience, 30, 620628.

KOCAGONCU, E., CLARKE, A., DEVEREUX, B. J. \& TYLER, L. K. 2017. Decoding the Cortical Dynamics of Sound-Meaning Mapping. J Neurosci, 37, 1312-1319.

LAKATOS, P., CHEN, C.-M., O'CONNELL, M. N., MILLS, A. \& SCHROEDER, C. E. 2007. Neuronal oscillations and multisensory interaction in primary auditory cortex. Neuron, 53, 279-292.

LAKATOS, P., KARMOS, G., MEHTA, A. D., ULBERT, I. \& SCHROEDER, C. E. 2008. Entrainment of neuronal oscillations as a mechanism of attentional selection. Science, 320, 110-113.

LAKATOS, P., MUSACCHIA, G., O'CONNEL, M. N., FALCHIER, A. Y., JAVITT, D. C. \& SCHROEDER, C. E. 2013. The specrotemporal filter mechanism of auditory selective attention. Neuron, 77, 750-761.

LAKATOS, P., SHAH, A. S., KNUTH, K. H., ULBERT, I., KARMOS, G. \& SCHROEDER, C. E. 2005. An oscillatory hierarchy controlling neuronal excitability and stimulus processing in the auditory cortex. Journal of Neurophysiology, 94, 1904-1911.

LEE, H., DEVLIN, J. T., SHAKESHAFT, C., STEWART, L. H., BRENNAN, A., GLENSMAN, J., PITCHER, K., CRINION, J., MECHELLI, A., FRACKOWIAK, R. S. J., GREEN, D. W. \& PRICE, C. J. 2007. Anatomical traces of vocabulary acquisition in the adolescent brain. Journal of Neuroscience, 27, 1184-1189.

LEE, Y.-S., MIN, N. E., WINGFIELD, A., GROSSMAN, M. \& PEELLE, J. E. 2016. Acoustic richness modulates the neural networks supporting intelligible speech processing. Hearing Research, 333, 108-117.

LEE, Y.-S., TURKELTAUB, P., GRANGER, R. \& RAIZADA, R. D. S. 2012. Categorical Speech Processing in Broca's Area: An fMRI Study Using Multivariate Pattern-Based Analysis. The Journal of Neuroscience, 32, 3942.

LEE, Y. S., WINGFIELD, A., MIN, N. E., KOTLOFF, E., GROSSMAN, M. \& PEELLE, J. E. 2018. Differences in hearing acuity among "normal-hearing" young adults modulate the neural basis for speech comprehension. eNeuro, ENEURO.0263-17.2018.

LEONARD, M. K., BAUD, M. O., SJERPS, M. J. \& CHANG, E. F. 2016. Perceptual restoration of masked speech in human cortex. Nat Commun, 7, 13619.

LERNER, Y., HONEY, C. J., SILBERT, L. J. \& HASSON, U. 2011. Topographic mapping of a hierarchy of temporal receptive windows using a narrated story. Journal of Neuroscience, 31, 2906-2915.

LIBERMAN, A. M., COOPER, F. S., SHANKWEILER, D. P. \& STUDDERT-KENNEDY, M. 1967. Perception of the speech code. Psychological Review, 74, 431-461.

LIBERMAN, A. M. \& MATTINGLY, I. G. 1985. The motor theory of speech perception revised. Cognition, 21, 1-36.

LIEBENTHAL, E., BINDER, J. R., SPITZER, S. M., POSSING, E. T. \& MEDLER, D. A. 2005. Neural substrates of phonemic perception. Cerebral Cortex, 15, 1621-1631.

LOTTO, A. J., HICKOK, G. S. \& HOLT, L. L. 2009. Reflections on mirror neurons and speech perception. Trends in Cognitive Sciences, 13, 110-114. 
LOVE, T., SWINNEY, D., WALENSKI, M. \& ZURIF, E. 2008. How left inferior frontal cortex participates in syntactic processing: Evidence from aphasia. Brain Lang, 107, 203-19.

LUCE, P. A. \& PISONI, D. B. 1998. Recognizing spoken words: The neighborhood activation model. Ear and Hearing, 19, 1-36.

LUO, H., LIU, Z. \& POEPPEL, D. 2010. Auditory cortex tracks both auditory and visual stimulus dynamics using low-frequency neuronal phase modulation. PLoS Biology, 8, e1000445.

LUO, H. \& POEPPEL, D. 2007. Phase patterns of neuronal responses reliably discriminate speech in human auditory cortex. Neuron, 54, 1001-1010.

MARSLEN-WILSON, W. D. \& TYLER, L. K. 1980. The temporal structure of spoken language processing. Cognition, 8, 1-71.

MATCHIN, W., GROULX, K. \& HICKOK, G. 2014. Audiovisual speech integration does not rely on the motor system: Evidence from articulatory suppression, the McGurk effect, and fMRI. Journal of Cognitive Neuroscience, 26, 606-620.

MATTYS, S. L., DAVIS, M. H., BRADLOW, A. R. \& SCOTT, S. K. 2012. Speech recognition in adverse conditions: A review. Language and Cognitive Processes, 27, 953-978.

MCCARTHY, R. A. \& WARRINGTON, E. K. 2016. Past, present, and prospects: Reflections 40 years on from the selective impairment of semantic memory (Warrington, 1975). $Q J$ Exp Psychol (Hove), 69, 1941-68.

MCGLONE, J. 1984. Speech comprehension after unilateral injection of sodium amytal. Brain Lang, 22, 150-7.

MCGURK, H. \& MACDONALD, J. 1976. Hearing lips and seeing voices. Nature, 264, 746748.

MESGARANI, N. \& CHANG, E. F. 2012. Selective cortical representation of attended speaker in multi-talker speech perception. Nature, 485, 233-237.

MESGARANI, N., CHEUNG, C., JOHNSON, K. \& CHANG, E. F. 2014. Phonetic feature encoding in human superior temporal gyrus. Science, 343, 1006-10.

MUMMERY, C. J., PATTERSON, K., PRICE, C. J., ASHBURNER, J., FRACKOWIAK, R. S. J. \& HODGES, J. R. 2000. A voxel-based morphometry study of Semantic Dementia: Relationship between temporal lobe atrophy and semantic memory. Annals of Neurology, 47, 36-45.

MUSZ, E. \& THOMPSON-SCHILL, S. L. 2017. Tracking competition and cognitive control during language comprehension with multi-voxel pattern analysis. Brain Lang, 165, 21 32.

MYERS, E. B., BLUMSTEIN, S. E., WALSH, E. \& ELIASSEN, J. 2009. Inferior frontal regions underlie the perception of phonetic category invariance. Psychol Sci, 20, 895 903.

NATH, A. R. \& BEAUCHAMP, M. S. 2011. Dynamic changes in superior temporal sulcus connectivity during perception of noisy audiovisual speech. Journal of Neuroscience, 31, 1704-1714.

NETA, M., MIEZIN, F. M., NELSON, S. M., DUBIS, J. W., DOSENBACH, N. U. F., SCHLAGGAR, B. L. \& PETERSEN, S. E. 2015. Spatial and temporal characteristics of error-related activity in the human brain. Journal of Neuroscience, 35, 253-266.

NORRIS, D. \& MCQUEEN, J. M. 2008. Shortlist B: A Bayesian model of continuous speech recognition. Psychological Review, 115, 357-395.

NOURSKI, K. V., STEINSCHNEIDER, M., OYA, H., KAWASAKI, H., JONES, R. D. \& HOWARD, M. A. 2014. Spectral organization of the human lateral superior temporal gyrus revealed by intracranial recordings. Cereb Cortex, 24, 340-52. 
OBLESER, J., ZIMMERMANN, J., VAN METER, J. \& RAUSCHECKER, J. P. 2007. Multiple stages of auditory speech perception reflected in event-related fMRI. Cerebral Cortex, 17, 2251-2257.

OKADA, K. \& HICKOK, G. 2009. Two cortical mechanisms support the integration of visual and auditory speech: A hypothesis and preliminary data. Neuroscience Letters, 452, 219 223.

OVERATH, T., KUMAR, S., STEWART, L., VON KRIEGSTEIN, K., CUSACK, R., REES, A. \& GRIFFITHS, T. D. 2010. Cortical mechanisms for the segregation and representation of acoustic textures. Journal of Neuroscience, 30, 2070-2076.

PAPOUTSI, M., STAMATAKIS, E. A., GRIFFITHS, J., MARSLEN-WILSON, W. D. \& TYLER, L. K. 2011. Is left fronto-temporal connectivity essential for syntax? Effective connectivity, tractography and performance in left-hemisphere damaged patients. NeuroImage, 58, 656-664.

PARK, H., KAYSER, C., THUT, G. \& GROSS, J. 2016. Lip movements entrain the observers' low-frequency brain oscillations to facilitate speech intelligibility. eLife, 5, e14521.

PATTERSON, K., NESTOR, P. J. \& ROGERS, T. T. 2007. Where do you know what you know? The representation of semantic knowledge in the human brain. Nature Reviews Neuroscience, 8, 976-987.

PEELLE, J. E. 2012. The hemispheric lateralization of speech processing depends on what "speech" is: A hierarchical perspective. Frontiers in Human Neuroscience, 6, 309.

PEELLE, J. E. 2014. Methodological challenges and solutions in auditory functional magnetic resonance imaging. Frontiers in Neuroscience, 8, 253.

PEELLE, J. E. 2017. Optical neuroimaging of spoken language. Language, Cognition and Neuroscience, 32, 847-854.

PEELLE, J. E. 2018. Listening effort: How the cognitive consequences of acoustic challenge are reflected in brain and behavior. Ear and Hearing, 39, 204-214.

PEELLE, J. E., COOKE, A., MOORE, P., VESELY, L. \& GROSSMAN, M. 2007. Syntactic and thematic components of sentence processing in progressive nonfluent aphasia and nonaphasic frontotemporal dementia. Journal of Neurolinguistics, 20, 482-494.

PEELLE, J. E. \& DAVIS, M. H. 2012. Neural oscillations carry speech rhythm through to comprehension. Frontiers in Psychology, 3, 320.

PEELLE, J. E., GROSS, J. \& DAVIS, M. H. 2013. Phase-locked responses to speech in human auditory cortex are enhanced during comprehension. Cerebral Cortex, 23, 1378-1387.

PEELLE, J. E. \& GROSSMAN, M. 2008. Language processing in frontotemporal dementia: A brief review. Language and Linguistics Compass, 2, 18-35.

PEELLE, J. E., JOHNSRUDE, I. S. \& DAVIS, M. H. 2010a. Hierarchical processing for speech in human auditory cortex and beyond. Frontiers in Human Neuroscience, 4, 51.

PEELlE, J. E., MCMILLAN, C., MOORE, P., GROSSMAN, M. \& WINGFIELD, A. 2004. Dissociable patterns of brain activity during comprehension of rapid and syntactically complex speech: Evidence from fMRI. Brain and Language, 91, 315-325.

PEELLE, J. E. \& SOMMERS, M. S. 2015. Prediction and constraint in audiovisual speech perception. Cortex, 68, 169-181.

PEELlE, J. E., TROIANI, V., GEE, J., MOORE, P., MCMILLAN, C., VESELY, L. \& GROSSMAN, M. 2008. Sentence comprehension and voxel-based morphometry in progressive nonfluent aphasia, semantic dementia, and nonaphasic frontotemporal dementia. Journal of Neurolinguistics, 21, 418-432. 
PEELLE, J. E., TROIANI, V., WINGFIELD, A. \& GROSSMAN, M. 2010b. Neural processing during older adults' comprehension of spoken sentences: Age differences in resource allocation and connectivity. Cerebral Cortex, 20, 773-782.

PETRIDES, M. \& PANDYA, D. N. 2009. Distinct parietal and temporal pathways to the homologues of Broca's area in the monkey. PLoS Biology, 7, e1000170.

PICHORA-FULLER, M. K., KRAMER, S. E., ECKERT, M. A., EDWARDS, B., HORNSBY, B. W. Y., HUMES, L. E., LEMKE, U., LUNNER, T., MATTHEN, M., MACKERSIE, C. L., NAYLOR, G., PHILLIPS, N. A., RICHTER, M., RUDNER, M., SOMMERS, M. S., TREMBLAY, K. L. \& WINGFIELD, A. 2016. Hearing impairment and cognitive energy: The framework for understanding effortful listening (FUEL). Ear and Hearing, $37,5 \mathrm{~S}-27 \mathrm{~S}$.

POWER, J. D. \& PETERSEN, S. E. 2013. Control-related systems in the human brain. Current Opinion in Neurobiology, 23, 223-228.

PRICE, A. R., BONNER, M. F., PEELLE, J. E. \& GROSSMAN, M. 2015. Converging evidence for the neuroanatomic basis of combinatorial semantics in the angular gyrus. Journal of Neuroscience, 35, 3276-3284.

PRICE, C. J., WISE, R., RAMSAY, S., FRISTON, K., HOWARD, D., PATTERSON, K. \& FRACKOWIAK, R. 1992. Regional response differences within the human auditory cortex when listening to words. Neuroscience Letters, 146, 179-182.

PRICE, C. J., WISE, R. J. S., WARBURTON, E. A., MOORE, C. J., HOWARD, D., PATTERSON, K., FRACKOWIAK, R. S. J. \& FRISTON, K. J. 1996. Hearing and saying: The functional neuro-anatomy of auditory word processing. Brain, 119, 919-931.

PRICE, D. L., DE WILDE, J. P., PAPADAKI, A. M., CURRAN, J. S. \& KITNEY, R. I. 2001. Investigation of acoustic noise on $15 \mathrm{MRI}$ scanners from $0.2 \mathrm{~T}$ to $3 \mathrm{~T}$. Journal of Magnetic Resonance Imaging, 13, 288-293.

RAIZADA, R. D. S. \& POLDRACK, R. A. 2007. Selective amplification of stimulus differences during categorical processing of speech. Neuron, 56, 726-740.

RAUSCHECKER, J. P. \& SCOTT, S. K. 2009. Maps and streams in the auditory cortex: nonhuman primates illuminate human speech processing. Nature Neuroscience, 12, 718 724.

RAVICZ, M. E., MELCHER, J. R. \& KIANG, N. Y.-S. 2000. Acoustic noise during functional magnetic resonance imaging. Journal of the Acoustical Society of America, 108, 16831696.

REILLY, J., GARCIA, A. \& BINNEY, R. J. 2016a. Does the sound of a barking dog activate its corresponding visual form? An fMRI investigation of modality-specific semantic access. Brain and Language, 159, 45-59.

REILLY, J., PEELLE, J. E., GARCIA, A. \& CRUTCH, S. J. 2016b. Linking somatic and symbolic representation in semantic memory: The dynamic multilevel reactivation framework. Psychonomic Bulletin and Review, 23, 1002-1014.

RIMMELE, J. M., ZION GOLUMBIC, E., SCHRÖGER, E. \& POEPPEL, D. 2015. The effects of selective attention and speech acoustics on neural speech-tracking in a multi-talker scene. Cortex, 68, 144-154.

RIMOL, L. M., SPECHT, K., WEIS, S., SAVOY, R. \& HUGDAHL, K. 2005. Processing of sub-syllabic speech units in the posterior temporal lobe: an fMRI study. Neuroimage, 26, 1059-67.

RODD, J. M., DAVIS, M. H. \& JOHNSRUDE, I. S. 2005. The neural mechanisms of speech comprehension: fMRI studies of semantic ambiguity. Cerebral Cortex, 15, 1261-1269. 
RODD, J. M., JOHNSRUDE, I. S. \& DAVIS, M. H. 2012. Dissociating frontotemporal contributions to semantic ambiguity resolution in spoken sentences. Cerebral Cortex, 22, 1761-1773.

RODD, J. M., LONGE, O. A., RANDALL, B. \& TYLER, L. K. 2010. The functional organisation of the fronto-temporal language system: Evidence from syntactic and semantic ambiguity. Neuropsychologia, 48, 1324-1335.

ROGALSKY, C. \& HICKOK, G. 2011. The role of Broca's area in sentence comprehension. Journal of Cognitive Neuroscience, 23, 1664-1680.

ROGALSKY, C., LOVE, T., DRISCOLL, D., ANDERSON, S. W. \& HICKOK, G. 2011. Are mirror neurons the basis of speech perception? Evidence from five cases with damage to the purported human mirror system. Neurocase, 17, 178-87.

ROGERS, J. C. \& DAVIS, M. H. 2017. Inferior Frontal Cortex Contributions to the Recognition of Spoken Words and Their Constituent Speech Sounds. Journal of Cognitive Neuroscience, 29, 919-936.

ROMANSKI, L. M. \& GOLDMAN-RAKIC, P. S. 2002. An auditory domain in primate prefrontal cortex. Nature Neuroscience, 5, 15-16.

ROMANSKI, L. M., TIAN, B., FRITZ, J., MISHKIN, M., GOLDMAN-RAKIC, P. S. \& RAUSCHECKER, J. P. 1999. Dual streams of auditory afferents target multiple domains in the primate prefrontal cortex. Nature Neuroscience, 2, 1131-1136.

SCHOMERS, M. R., KIRILINA, E., WEIGAND, A., BAJBOUJ, M. \& PULVERMULLER, F. 2015. Causal Influence of Articulatory Motor Cortex on Comprehending Single Spoken Words: TMS Evidence. Cereb Cortex, 25, 3894-902.

SCHROEDER, C. E. \& LAKATOS, P. 2009. Low-frequency neuronal oscillations as instruments of sensory selection. Trends in Neurosciences, 32, 9-18.

SCHROEDER, C. E., LAKATOS, P., KAJIKAWA, Y., PARTAN, S. \& PUCE, A. 2008. Neuronal oscillations and visual amplification of speech. Trends in Cognitive Sciences, 12, 106-113.

SCOTT, S. K., BLANK, C. C., ROSEN, S. \& WISE, R. J. S. 2000. Identification of a pathway for intelligible speech in the left temporal lobe. Brain, 123, 2400-2406.

SEKIYAMA, K., KANNO, I., MIURA, S. \& SUGITA, Y. 2003. Auditory-visual speech perception examined by fMRI and PET. Neuroscience Research, 47, 277-287.

SELTZER, B., COLA, M. G., GUTIERREZ, C., MASSEE, M., WELDON, C. \& CUSICK, C. G. 1996. Overlapping and nonoverlapping cortical projections to cortex of the superior temporal sulcus in the rhesus monkey: double anterograde tracer studies. J Comp Neurol, 370, 173-90.

SELTZER, B. \& PANDYA, D. N. 1989. Frontal lobe connections of the superior temporal sulcus in the rhesus monkey. Journal of Comparative Neurology, 281, 97-113.

SHANNON, R. V., ZENG, F.-G., KAMATH, V., WYGONSKI, J. \& EKELID, M. 1995. Speech recognition with primarily temporal cues. Science, 270, 303-304.

SKIPPER, J. I., VAN WASSENHOVE, V., NUSBAUM, H. C. \& SMALL, S. L. 2007. Hearing lips and seeing voices: how cortical areas supporting speech production mediate audiovisual speech perception. Cereb Cortex, 17, 2387-99.

SOHOGLU, E., PEELLE, J. E., CARLYON, R. P. \& DAVIS, M. H. 2012. Predictive top-down integration of prior knowledge during speech perception. Journal of Neuroscience, 32, 8443-8453.

SPECHT, K. \& REUL, J. 2003. Functional segregation of the temporal lobes into highly differentiated subsystems for auditory perception: an auditory rapid event-related fMRItask. Neuroimage, 20, 1944-54. 
STEINSCHNEIDER, M., NOURSKI, K. V., KAWASAKI, H., OYA, H., BRUGGE, J. F. \& HOWARD, M. A., 3RD 2011. Intracranial study of speech-elicited activity on the human posterolateral superior temporal gyrus. Cereb Cortex, 21, 2332-47.

SUMBY, W. H. \& POLLACK, I. 1954. Visual contribution to speech intelligibility in noise. Journal of the Acoustical Society of America, 26, 212-215.

SWINNEY, D. \& ZURIF, E. 1995. Syntactic processing in aphasia. Brain Lang, 50, 225-39.

THOMPSON-SCHILL, S. L., D'ESPOSITO, M., AGUIRRE, G. K. \& FARAH, M. J. 1997. Role of left inferior prefrontal cortex in retrieval of semantic knowledge: A reevaluation. Proceedings of the National Academy of Sciences, 94, 14792-14797.

TYLER, L. K., MARSLEN-WILSON, W. D., RANDALL, B., WRIGHT, P., DEVEREUX, B. J., ZHUANG, J., PAPOUTSI, M. \& STAMATAKIS, E. A. 2011. Left inferior frontal cortex and syntax: function, structure and behaviour in patients with left hemisphere damage. Brain, 134, 415-431.

TYLER, L. K., SHAFTO, M. A., RANDALL, B., WRIGHT, P., MARSLEN-WILSON, W. D. \& STAMATAKIS, E. A. 2010. Preserving syntactic processing across the adult life span: The modulation of the frontotemporal language system in the context of age-related atrophy. Cerebral Cortex, 20, 352-364.

VADEN JR., K. I., KUCHINSKY, S. E., CUTE, S. L., AHLSTROM, J. B., DUBNO, J. R. \& ECKERT, M. A. 2013. The cingulo-opercular network provides word-recognition benefit. Journal of Neuroscience, 33, 18979-18986.

VADEN JR., K. I., TEUBNER-RHODES, S., AHLSTROM, J. B., DUBNO, J. R. \& ECKERT, M. A. 2017. Cingulo-opercular activity affects incidental memory encoding for speech in noise. NeuroImage, 157, 381-387.

VAN ENGEN, K. J. \& PEELLE, J. E. 2014. Listening effort and accented speech. Frontiers in Human Neuroscience, 8, 577.

VAN ENGEN, K. J., XIE, Z. \& CHANDRASEKARAN, B. 2017. Audiovisual sentence recognition not predicted by susceptibility to the McGurk effect. Attention, Perception, and Psychophysics, 79, 396-403.

VENEZIA, J. H., FILLMORE, P., MATCHIN, W., ISENBERG, A. L., HICKOK, G. \& FRIDRIKSSON, J. 2016. Perception drives production across sensory modalities: A network for sensorimotor integration of visual speech. Neuroimage, 126, 196-207.

WHITNEY, C., KIRK, M., O'SULLIVAN, J., LAMBON RALPH, M. A. \& JEFFERIES, E. 2011. The neural organization of semantic control: TMS evidence for a distributed network in left inferior frontal and posterior middle temporal gyrus. Cerebral Cortex, 21, 1066-1075.

WILD, C. J., YUSUF, A., WILSON, D., PEELLE, J. E., DAVIS, M. H. \& JOHNSRUDE, I. S. 2012. Effortful listening: The processing of degraded speech depends critically on attention. Journal of Neuroscience, 32, 14010-14021.

WINGFIELD, A., PEELLE, J. E. \& GROSSMAN, M. 2003. Speech rate and syntactic complexity as multiplicative factors in speech comprehension by young and older adults. Aging, Neuropsychology, and Cognition, 10, 310-322.

WÖSTMANN, M., FIEDLER, L. \& OBLESER, J. 2017. Tracking the signal, cracking the code: Speech and speech comprehension in non-invasive human electrophysiology. Language, Cognition and Neuroscience, 32, 855-869.

ZEMPLENI, M.-Z., RENKEN, R., HOEKS, J. C. J., HOOGDUIN, J. M. \& STOWE, L. A. 2007. Semantic ambiguity processing in sentence context: Evidence from event-related fMRI. NeuroImage, 34, 1270-1279. 
ZHUANG, J., TYLER, L. K., RANDALL, B., STAMATAKIS, E. A. \& MARSLEN-WILSON, W. D. 2014. Optimially efficient neural systems for processing spoken language. Cerebral Cortex, 24, 908-918.

ZION GOLUMBIC, E., DING, N., BICKEL, S., LAKATOS, P., SCHEVON, C. A., MCKHANN, G. M., GOODMAN, R. R., EMERSON, R., MEHTA, A. D., SIMON, J. Z., POEPPEL, D. \& SCHROEDER, C. E. 2013. Mechanisms underlying selective neuronal tracking of attended speech at a "cocktail party". Neuron, 77, 980-991. 